\title{
Numerical Model Research on Rotational Performance of Beam-Column High-Strength Bolt Extension End-Plate Connection Node
}

\author{
Xiao Lang \\ School of Civil Engineering and Architecture, Southwest University of Science and Technology, Mianyang, China \\ Email: xl15881650881@126.com
}

How to cite this paper: Lang, X. (2021) Numerical Model Research on Rotational Performance of Beam-Column HighStrength Bolt Extension End-Plate Connection Node. Open Journal of Modelling and Simulation, 9, 231-245.

https://doi.org/10.4236/ojmsi.2021.93015

Received: April 27, 2021

Accepted: June 21, 2021

Published: June 24, 2021

Copyright $\odot 2021$ by author(s) and Scientific Research Publishing Inc. This work is licensed under the Creative Commons Attribution International License (CC BY 4.0). http://creativecommons.org/licenses/by/4.0/

\begin{abstract}
The high-strength bolted end plate connection is widely used in the construction industry with its green environmental protection and excellent seismic performance. The joints of the joints are semi-rigid, the force performance is extremely complicated, and the experimental research cost is relatively high, and the cycle is very long. Therefore, the establishment of an efficient numerical model is of great significance for evaluating the force performance of high-strength bolt end plates. In this paper, the influence of different material models on the rotation performance of the joint is studied by numerical simulation, and the bending moment-rotation curve is obtained. The numerical simulation and the experimental results are in good agreement, so as to provide a reference for the design and application of this kind of joint.
\end{abstract}

\section{Keywords}

High-Strength Bolt, Rotation Performance, Material Model,

Numerical Model

\section{Preface}

Steel structure beam-column high-strength bolt extension end plate connection is a typical semi-rigid connection. Under load, the rotation performance of the semi-rigid connection is an important mechanical performance, and the bending moment-angle curve is an important characterization of the rotation performance of the connection node, which is reasonable the material constitutive model can accurately describe the most realistic rotation performance of the beam-column node. Experimental research cannot reflect the changes in the internal force of the structure during the test, and often only the final phenome- 
non of the test can be seen. However, the finite element analysis can clearly reflect the force situation inside the structure at any time during the test.

Krishnamurthy first conducted finite element analysis on the end plate connection nodes, studied the end plate connection without stiffening ribs and two rows of four bolts in the tension zone, and proposed a design method [1] [2]. Subsequently, Maxwell also carried out some finite element analysis of end plate connection nodes and their experimental verification work [3]. Shi Gang and Liu Wei [4] [5] used ANSYS to carry out finite element calculations on the static test specimens, and verified the reliability of the finite element method to analyze the end plate connection, and obtained the bending moment curve but the test bending moment There is a big difference in the curves. Guo Chao [6] used different finite element methods to simulate. The ANSYS finite element simulation methods of typical high-strength bolt extension end-plate connections are compared and studied, and the characteristics of various finite element simulation methods are analyzed. Wang Yan [7] analyzed the influence of end plate thickness, bolt diameter, node domain stiffeners, end plate stiffeners, etc. on the tension distribution and bearing capacity of high-strength bolts in the extension end plate connection of high-strength bolts. Wang Dongyang [8] studied the static performance of the end plate connection node with super large bearing capacity through static loading test and finite element numerical simulation; combined with the installation process of the test piece, studied the tightening of high-strength bolts in the end plate connection Sequential and pre-tensioning strain relaxation issues. Sun Ying [9] used ANSYS finite element model to study the effect of shear force, bolt diameter, bolt arrangement, end plate thickness, end plate stiffeners, and column node domains on the tension distribution of bolt groups when the node is in the elastic and plastic stage.

The analysis found that the simplification of the material model will affect the accuracy of the simulation results, especially the nodal bending moment curve. At present, the European norm EC3 [10] regards the yield strength $f_{y}$ as a sign of the ultimate bearing capacity, and regards the material before the stress reaches the service strength as a complete elastic body, and the material after the stress exceeds the yield strength as a complete plastic body. In order to simplify the model, Shi Gang and Liu Wei [4] [5] simplified the material constitutive of steel to an ideal elastoplastic model as shown in Figure 1. Guo Chao, Wang Yan [6] [7] and others believed that the stress strengthening of the material after yielding cannot be ignored and proposed a three-line model as shown in Figure 2. Wang Dong yang, Sun Ying [8] [9] and others believe that the yield platform effect of materials cannot be ignored. When the yield stress of the steel reaches the yield strength, the steel cannot withstand a greater load temporarily, and the accompanying production when the residual strain reaches between 0.0015 and 0.025, the four-wire material model should be used as shown in Figure 3.

This paper compares the ideal elastoplastic, three-line and four-line material models through numerical simulation and analyzes that the four-line material model can simulate the bending moment curve at the node most accurately. 


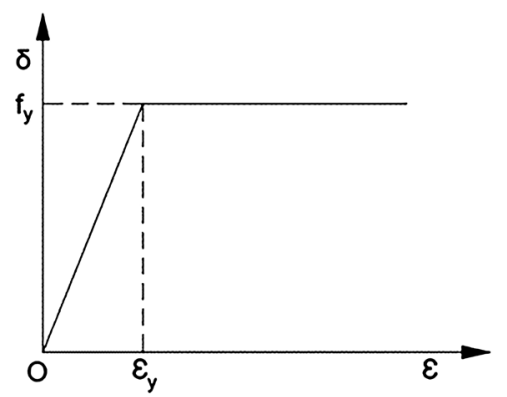

Figure 1. Simplified model of ideal material.

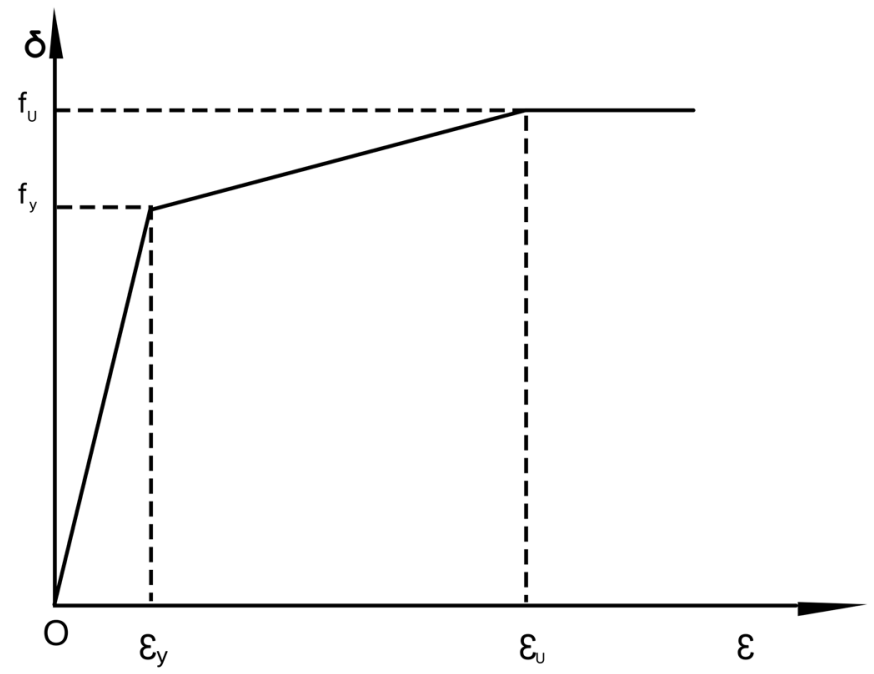

Figure 2. Three-line material model.

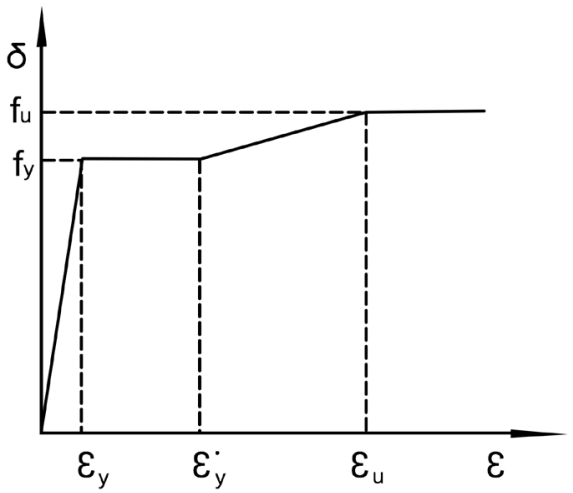

Figure 3. Four-line material mode.

\section{Establishment of Finite Element Model}

\subsection{Geometric Model}

In order to verify the accuracy of the model, this paper selects the experimental model of Dr. Shi Gang from Tsinghua University. The beams and columns are all welded H-shaped steels. The beam cross-section dimensions are both $300 \mathrm{~mm}$ $\times 200 \mathrm{~mm} \times 8 \mathrm{~mm} \times 12 \mathrm{~mm}$, and the column cross-section dimensions are both $300 \mathrm{~mm} \times 250 \mathrm{~mm} \times 8 \mathrm{~mm} \times 12 \mathrm{~mm}$. The column flange is locally thickened 
within $100 \mathrm{~mm}$ of the upper and lower extension edges of the end plate, and the thickness is the same as that of the end plate. The geometric model shown in Figure 4 is established through the finite element simulation software. The bolts are 10.9 grade friction type high-strength bolts. There are two types: M20 and M24. Except for high-strength bolts, all other components and parts are made of Q345 steel. The test piece uses 10.9 grade M24 high-strength bolts, the end plate thickness is $20 \mathrm{~mm}$, and the detailed dimensions of the joints are shown in Figure 5. The stiffeners at the overhanging end plates are triangular, and the two right-angle sides are both $100 \mathrm{~mm}$ long and $10 \mathrm{~mm}$ thick.

\subsection{Unit Type}

For each part of the test piece, solid45 elements are used. The contact between the end plate and the column flange and the contact between the nut and the column flange are considered to create a three-dimensional contact pair for simulation. The three-dimensional eight-node surface-surface contact element CONTA174 and the three-dimensional Simulation of the target unit TARGE170. The high-strength bolt generates a three-dimensional pre-tightening unit PRETS179 through the PSMESH command to apply pre-tension [11].

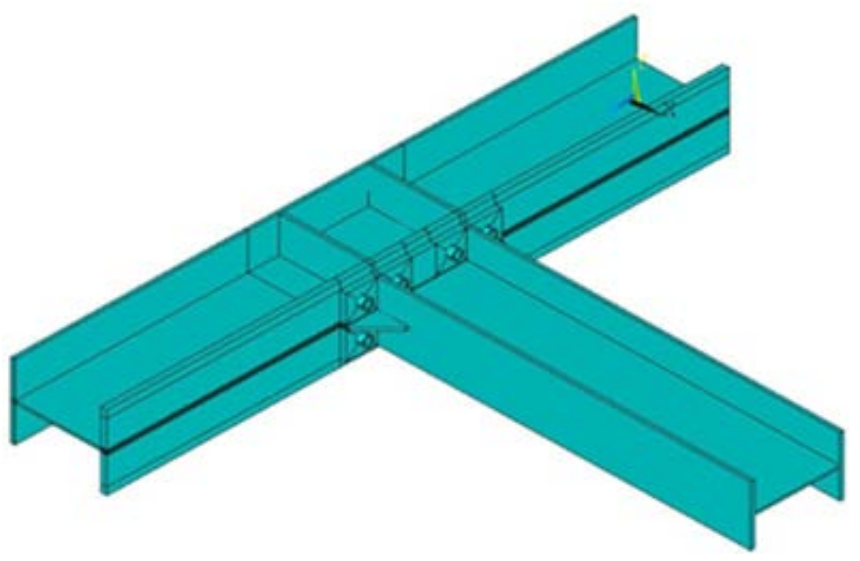

Figure 4. Geometric model.

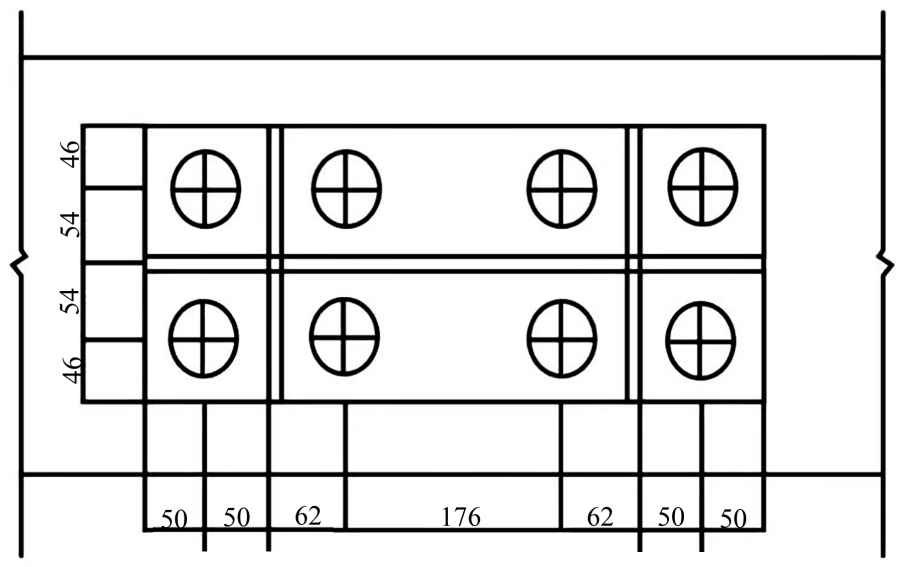

Figure 5. Node detail. 


\subsection{Meshing}

In this paper, all the grids of the beam-column model are divided into hexahedral grids by sweeping. In order to save calculation time, the size of the mesh refinement at the node domain is $4 * 4 * 4$, and the rest of the grid is $4{ }^{*} 10^{*} 12$. The meshing of the end plates and bolts is shown in Figure 6 and Figure 7.

\subsection{Material Model}

Material parameters are obtained by static tensile test. The tensile test piece is a rectangular specimen, which is then processed into a material test piece according to the "Metal Tensile Test Specimen" (GB6397-86), and the loading is carried out in accordance with the "Metal Tensile Test Method" (GB228-87). The material properties of steel are measured, including yield strength $f_{y}$, yield strain $\varepsilon_{y}$, yield plateau strain $\varepsilon_{y}^{\prime}$, tensile strength $f_{u}$, ultimate strain $\varepsilon_{u}$ and elastic modulus $E$ are shown in Table 1.

The steel used in this paper is all Q345 structural steel, and its stress-strain relationship takes into account the ideal elastoplastic model of the material. The three-line follow-up strengthening model and the four-line follow-up strengthening model are shown in Table 2.

According to the product quality assurance data, the stress-strain relationship of high-strength bolts (including bolt heads, bolt rods and nuts) adopts a trilinear model [12]. The yield strength and ultimate strength and the corresponding strain data are shown in Table 3.

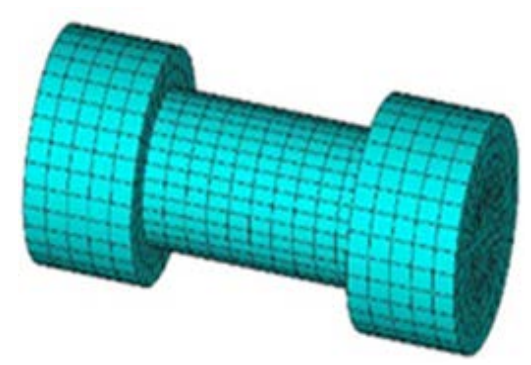

Figure 6. Meshing of bolts.

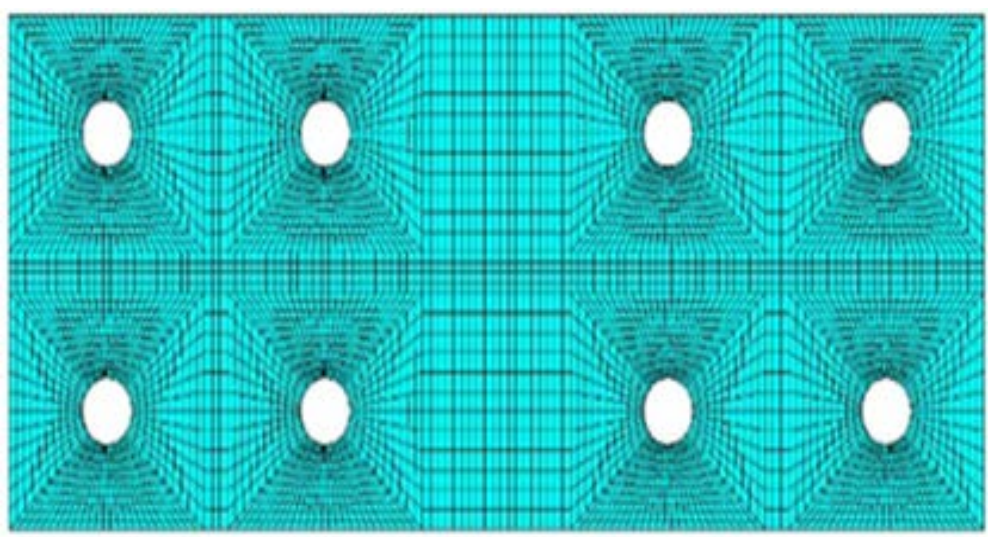

Figure 7. Meshing of end plates. 
Table 1. Material property test results.

\begin{tabular}{ccccccc}
\hline $\begin{array}{c}\text { Specimen } \\
\text { number }\end{array}$ & $\begin{array}{c}\text { Specimen } \\
\text { thickness }\end{array}$ & $\begin{array}{c}\text { Yield } \\
\text { Strength } \\
f_{y}(\mathrm{MPa})\end{array}$ & $\begin{array}{c}\text { Yield strain } \\
\varepsilon_{y}\end{array}$ & $\begin{array}{c}\text { modulus of } \\
\text { elasticity } \\
E(\mathrm{MPa})\end{array}$ & $\begin{array}{c}\text { tensile } \\
\text { strength } \\
f_{u}(\mathrm{MPa})\end{array}$ & $\begin{array}{c}\text { Ultimate } \\
\text { strain } \\
\varepsilon_{u}\end{array}$ \\
\hline C8-1 & 8 & 376.5 & 0.00197 & 189,789 & 592.6 & 0.144 \\
C8-2 & 8 & 379.6 & 0.00194 & 190,243 & 586.4 & 0.137 \\
C8-3 & 8 & 388.2 & 0.00199 & 191,877 & 589.3 & 0.156 \\
C20-1 & 20 & 358.9 & 0.00177 & 201,898 & 559.5 & 0.099 \\
C20-2 & 20 & 365.8 & 0.00179 & 203,270 & 556.4 & 0.076 \\
C20-3 & 20 & 363.4 & 0.00179 & 202,425 & 557.1 & 0.085 \\
average value & - & 372.1 & 0.00188 & 196,583 & 573.5 & 0.11 \\
\hline
\end{tabular}

Table 2. Material model.

\begin{tabular}{cccccccc}
\hline \multirow{2}{*}{ Table Head } & \multicolumn{7}{c}{ Table Column Head } \\
\cline { 2 - 7 } & $f_{y}(\mathrm{MPa})$ & $\varepsilon_{y}$ & $E(\mathrm{MPa})$ & $\varepsilon_{y}^{\prime}$ & $f_{u}$ & $(\mathrm{MPa})$ & $\varepsilon_{u}$ \\
\hline Ideal elastoplastic model & 372.1 & 0.00188 & 196,583 & $/$ & $/$ & $/$ \\
Three-line model & 372.1 & 0.00188 & 196,583 & $/$ & 573.5 & 0.11 \\
Four linear model & 372.1 & 0.00188 & 196,583 & 0.13 & 573.5 & 0.11 \\
\hline
\end{tabular}

Table 3. Material properties of high-strength bolts.

\begin{tabular}{cccc}
\hline Stress $(\mathrm{MPa})$ & 995 & 1160 & 1160 \\
\hline Strain & 0.00483 & 0.136 & 0.15 \\
\hline
\end{tabular}

All materials are isotropic, and the Poisson's ratio is 0.3 . The yield criterion adopts the von Mises yield criterion. After the material yields, the flow theory and the follow-up strengthening criterion are adopted. The anti-slip coefficient of the friction surface of the end plate is 0.44 [13].

\subsection{Contact Settings}

The GUI is used to create contact pairs through the contact wizard. This article considers three contact pairs, respectively, the first pair of contacts are nut and column flange, the second pair of contacts are nut and end plate, and the third pair of contacts are end plate and column flange. According to the principle of selecting the contact surface and the target surface, in the first pair of contact, the column flange is set as the target surface, and the surface of the nut and the column flange is set as the contact surface; the second pair of contact middle end plate surface is set as the target surface, and the screw The contact surface between the cap and the end plate is set as the contact surface; the third pair of contact center column flange and the end plate contact surface is set as the target surface, and the end plate and the column flange contact surface are set as the contact surface. 


\subsection{Boundary Condition Calculation Process}

The pre-tension of the high-strength bolt is applied in the generated three-dimensional pre-tension unit PRETS179 through the SLOAD command. The pre-tension takes the standard design value, that is, M24 takes $225 \mathrm{kN}$. The boundary condition of the test piece is considered as the fixed constraint of the left and right ends of the column. The analysis and calculation process is divided into three load steps: the first step is to load the bolt with pretension; the second step is to lock the displacement generated by the bolt pretension in the first step; The third step is to impose a forced displacement load on the beam end according to the test situation. The first and second steps adopt small deformation static analysis, and the third step adopts large deformation static analysis, that is, considering the second-order effect, automatic time steps are used in all three load steps [14]. The magnitude of the displacement load refers to the measured displacement value in the test. This loading sequence is fully in line with the actual test process of the specimen and the sequence of the bolt forces in the actual project.

\section{Comparison of Results of Three Material Models}

It can be seen from Figure 2 that the ideal elastoplastic material model oversimplifies the actual material stress-strain relationship of the steel, which usually results in the simulation results of the bending moment curve and the experimental results in the elastic stage, and once the material enters plasticity, the simulation The ultimate bearing capacity will be much lower than the actual bearing capacity as shown in Figure 8(a). Through simulation, it is found that when the three-line model is used, the problem of no strengthening stage of the bending moment curve is well solved as shown in Figure 8(b). The three-line material model is shown in Figure 3 to determine the yield strength of the material and the corresponding yield strain. And the ultimate strength and the corresponding ultimate strain, but this usually causes the tangent modulus $E_{s t}$ to be smaller than the actual value, which is due to the residual strain when the material yields. The four-linear material model can well reflect the bending moment-angle curve of the beam-column node as shown in Figure 8(c). Although this model can well describe the real situation of the bending moment and corner curve response node, it needs to determine the material The five parameters of yield strength, yield strain, yield platform length, ultimate strength and ultimate strain, especially the value of steel yield platform length $\varepsilon_{y}^{\prime}$ are extremely unstable, and the value of $\varepsilon_{y}^{\prime}$ must be determined within a reasonable range. Therefore, in order to make the simulation results more suitable for the actual situation, this paper considers the influence of the yield platform and adopts the four-linear material model as shown in Figure 4, and the comparison of the simulation results of the three simplified material models is shown in Figure 8(d).

Through the comparison of Figure 8(d), it is found that the four-line material model has the highest degree of fit with the nodal bending moment curve. The 


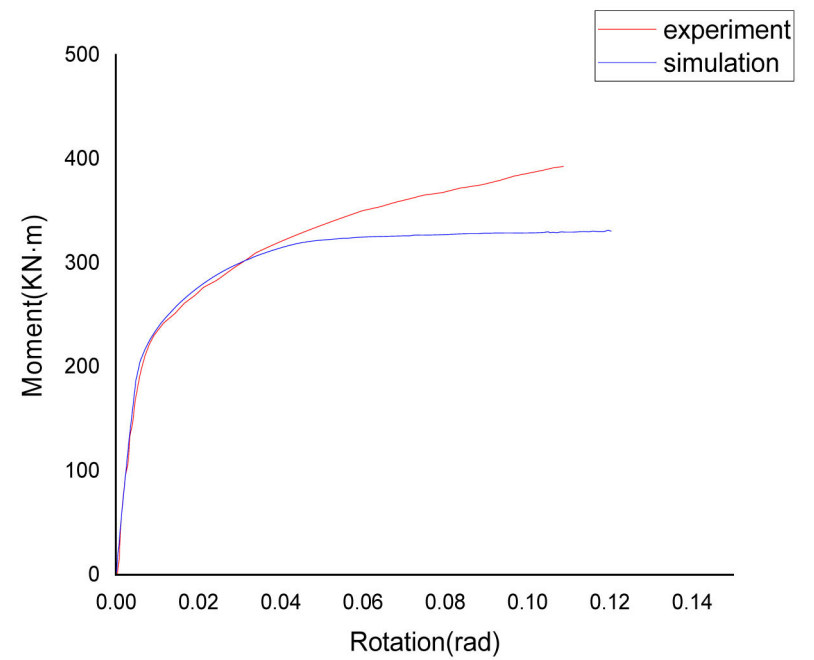

(a)

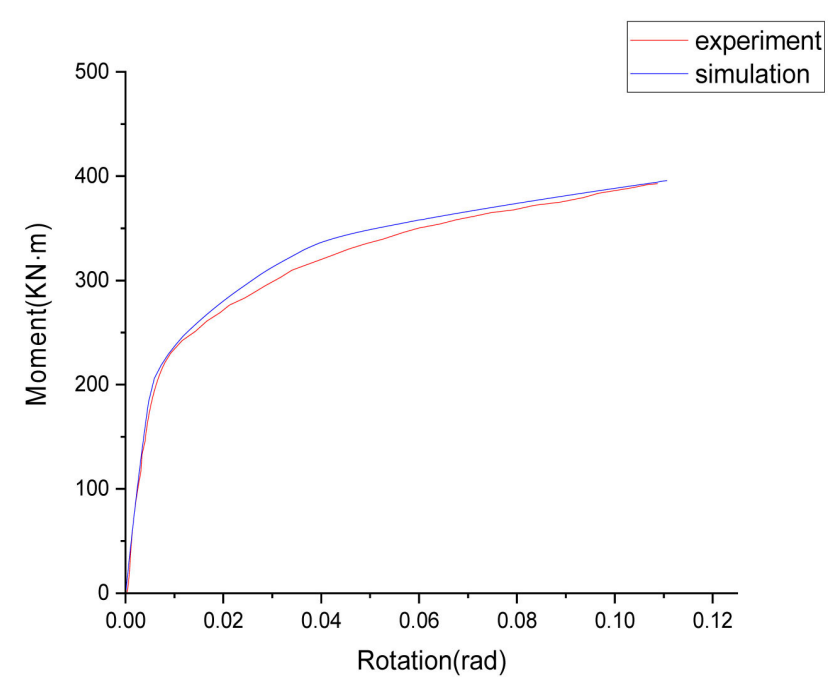

(c)

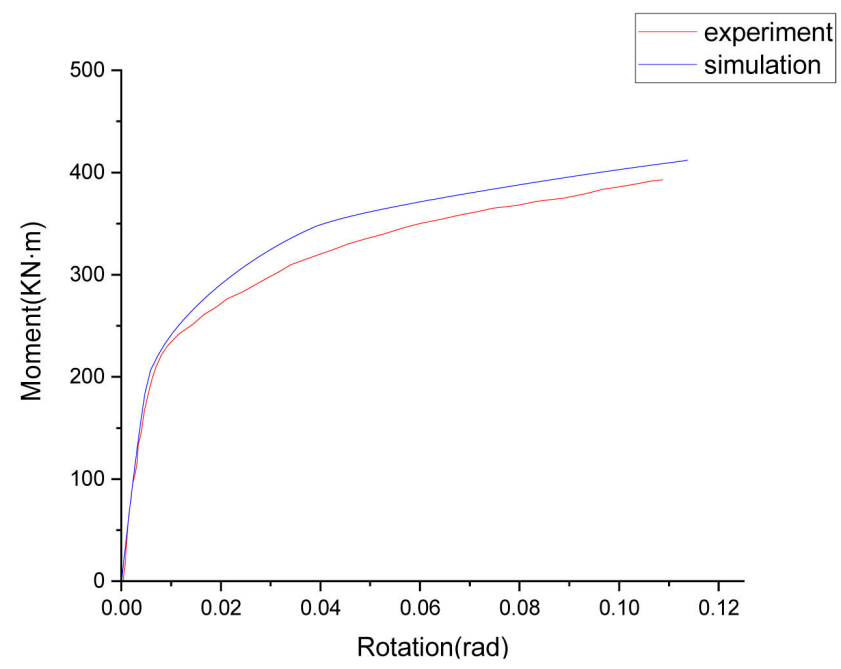

(b)

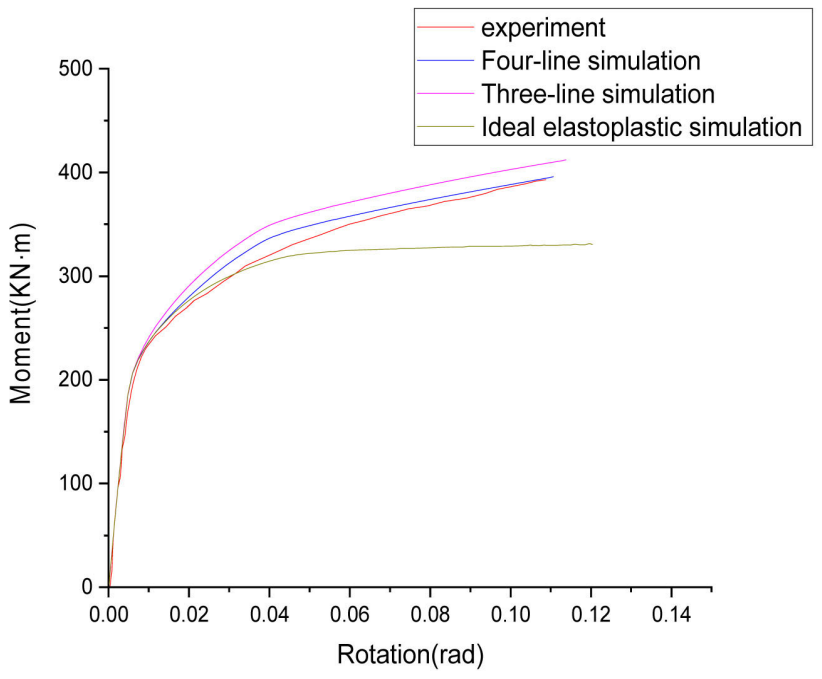

(d)

Figure 8. Comparison of simulated and experimental bending moment curves. (a) Ideal elastoplastic simulation results; (b) Three-line material model simulation results; (c) Four-wire material model simulation results; (d) Material model simplified simulation results.

ideal elastoplastic model and the three-line material model are very different from the experimental curve, which is sufficient to explain the yield of the steel. The platform cannot be ignored when the material model is simplified.

\section{Validation of Finite Element Model}

From the perspective of the overall deformation of the nodes in Figure 9 and Figure 10, the simulated beam-column node deformation cloud diagram in this paper is very consistent with the final deformation diagram of the experiment done by Shi Gang of Tsinghua University. Partially damaged under pressure.

The simulation data in this paper is compared and analyzed with Shi Gang's experiment from multiple angles, including four aspects: bending moment angle curve, bending moment shear angle curve, bending moment gap angle curve, 


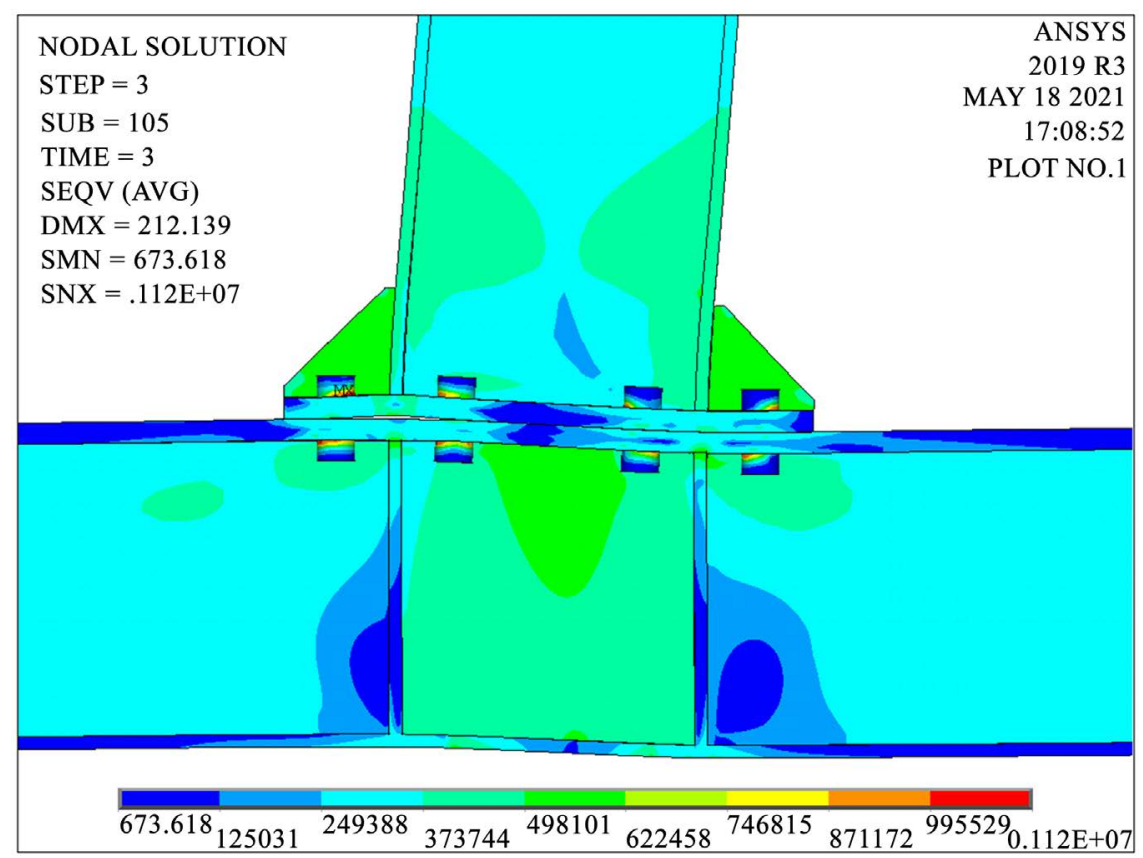

Figure 9. Simulated deformation diagram.

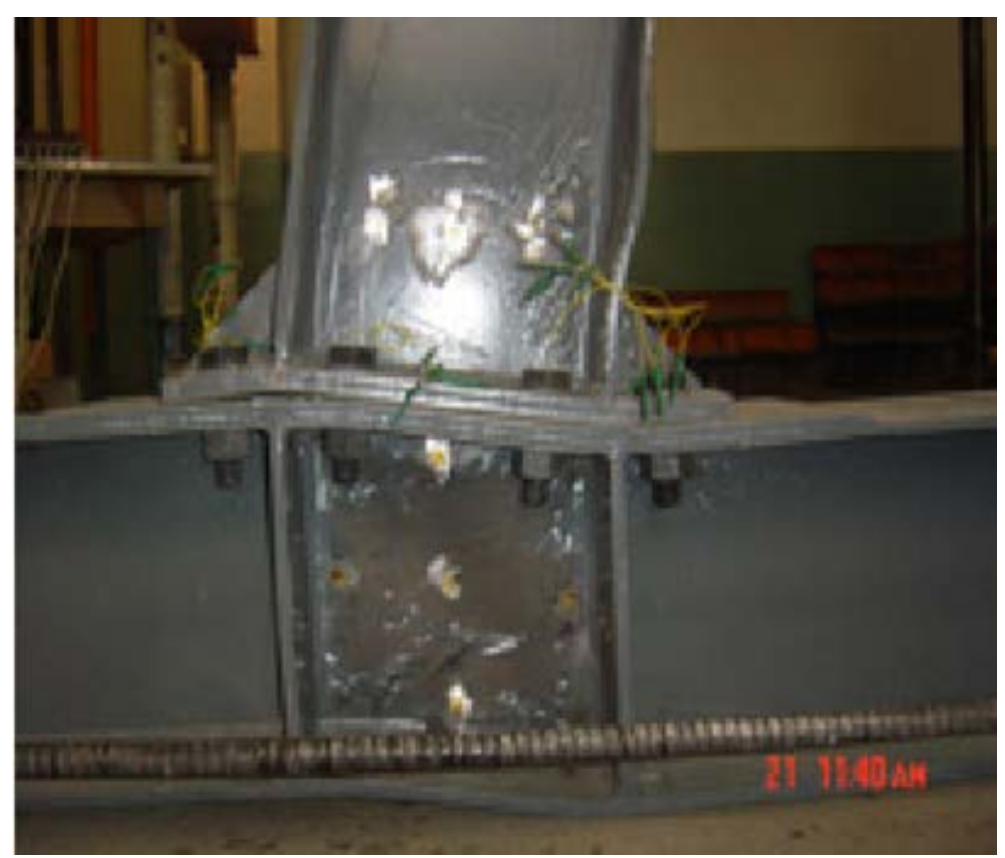

Figure 10. Deformation diagram of Shi Gang.

and loading force displacement curve to verify the four-line material model. The reliability of the finite element model is shown in Figures 11-14.

Through the above analysis, it can be seen that regardless of the initial rigidity, ultimate bending moment, or bending moment-angle curve of the semi-rigid connection of the overhanging end plate, the results obtained by ANSYS are in good agreement with the results obtained by the test, which is to further analyze the joint rotation capacity Impact provides a solid foundation and feasibility. 


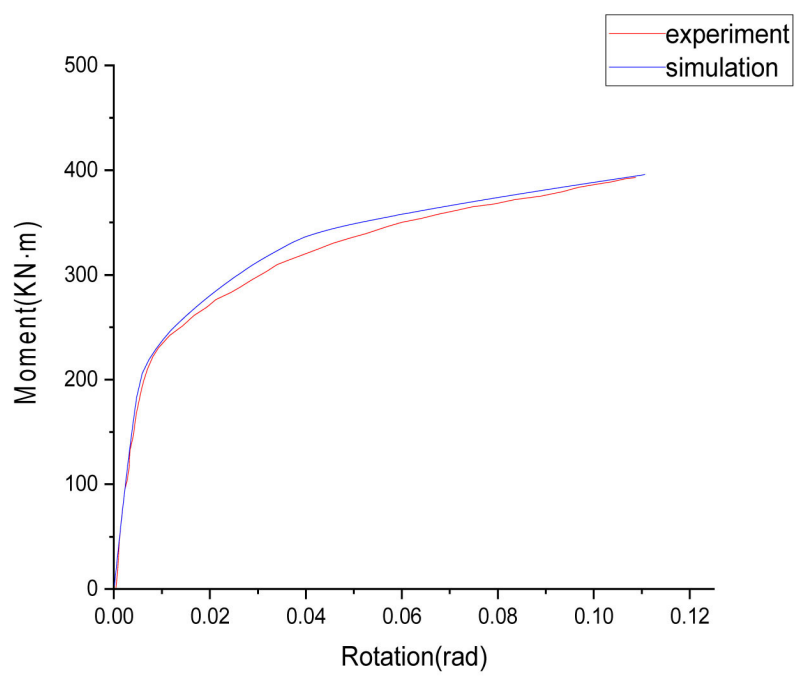

Figure 11. Comparison of bending moment and corner curves.

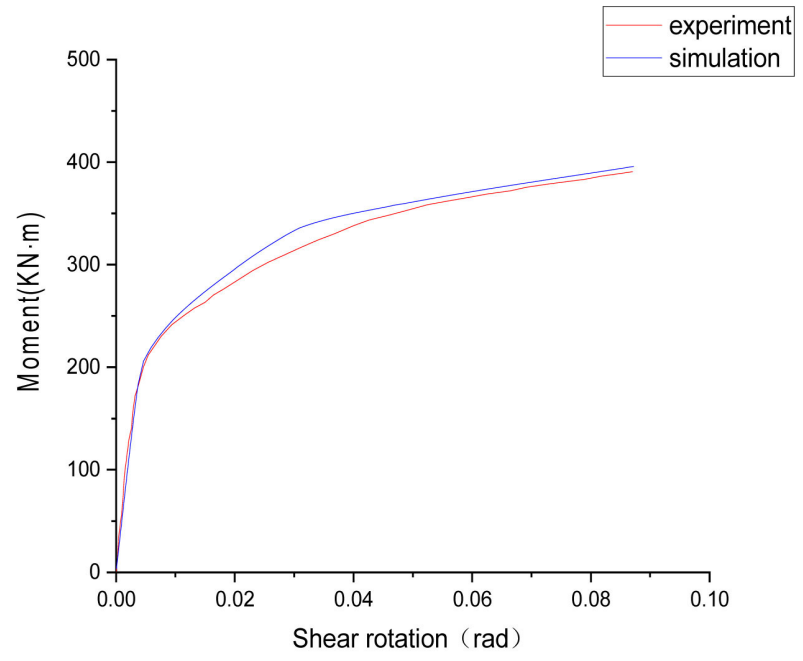

Figure 12. Comparison of bending moment and shear corners.

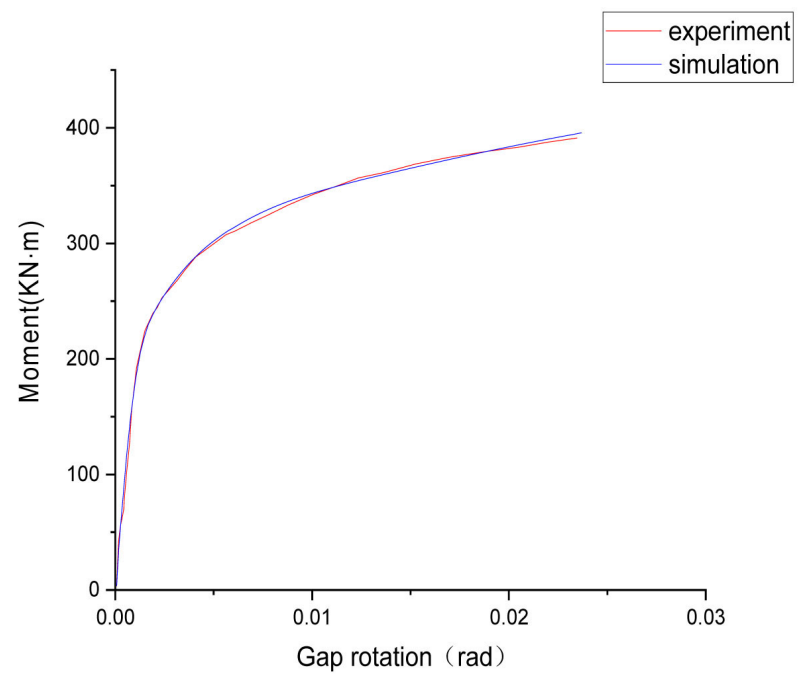

Figure 13. Comparison of bending moment clearance angles. 


\section{Finite Element Model Analysis}

The prestress distribution of bolts after the completion of the first two loading steps of ANSYS simulation is shown in Figure 15 and Figure 16, respectively. The stress distribution cloud diagrams of the end plate under compression are shown in Figure 17 and Figure 18. The third step after the beam end load is applied The acting end plate is subjected to uniform compressive stress, and the bolt locks the beam end plate and the column flange at this time. After the beam end load is applied in the third step, the stress and frictional stress distributions of the end plates are shown in Figure 19 and Figure 20. The von mise stress at the connection between the upper flange of the beam and the end plate is the largest, and the separation of the connecting end plate of the upper flange of the beam and the column flange results in no friction stress distribution on the left side of the end plate. The stress of the bolt and the stress distribution in the $\mathrm{x}$-direction are shown in Figure 21 and Figure 22. It can be seen that the

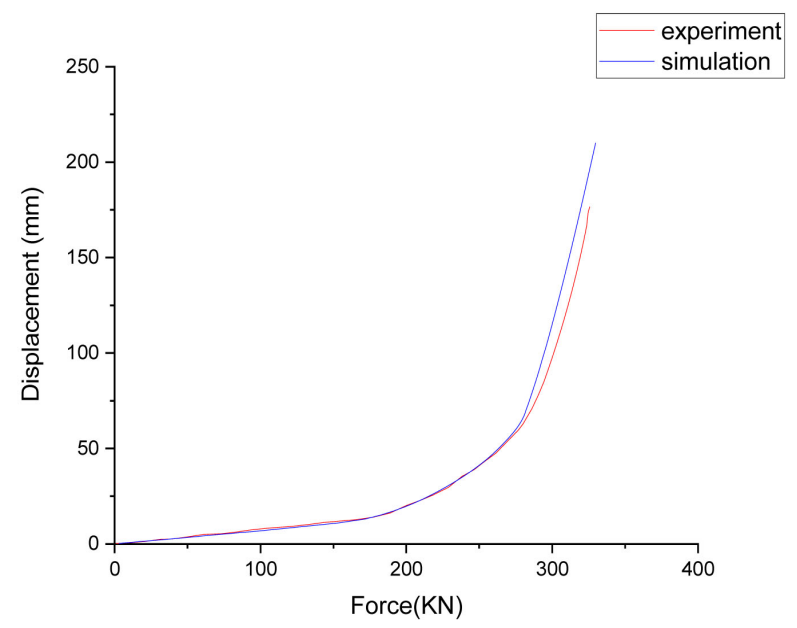

Figure 14. Comparison of load displacement curves.

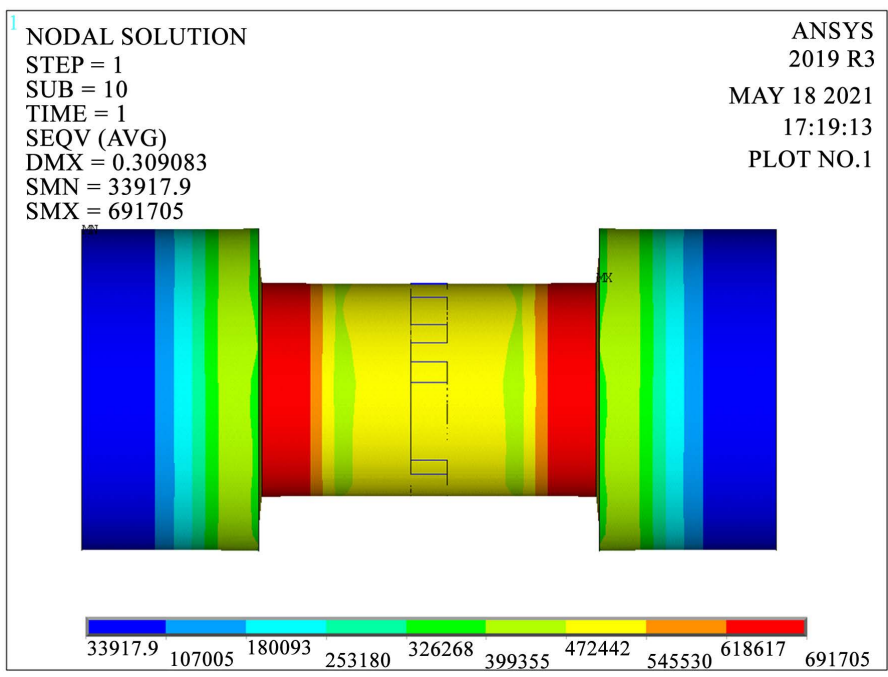

Figure 15. Bolt first load stress distribution. 


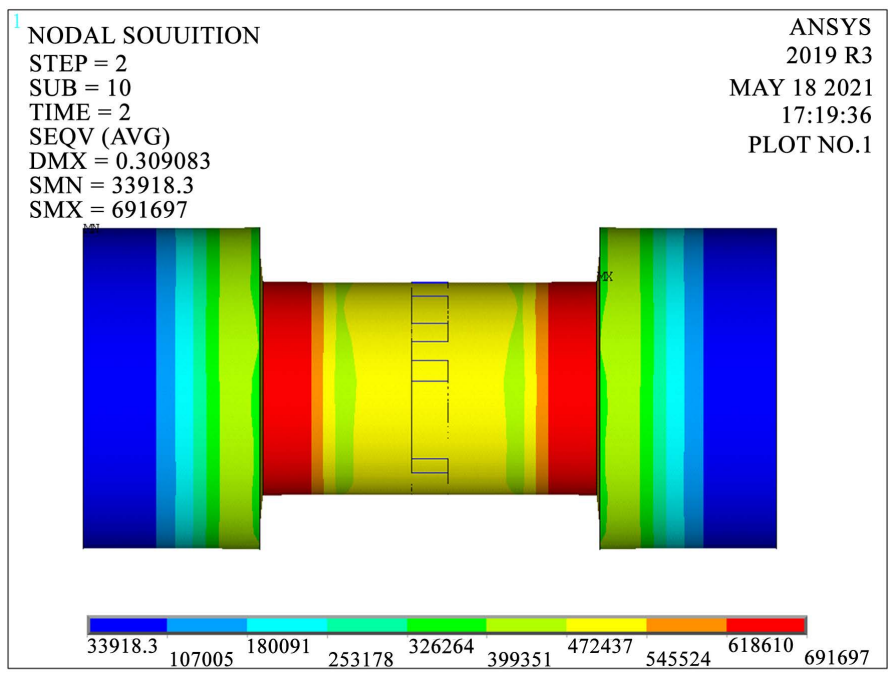

Figure 16. Bolt second step load stress distribution.

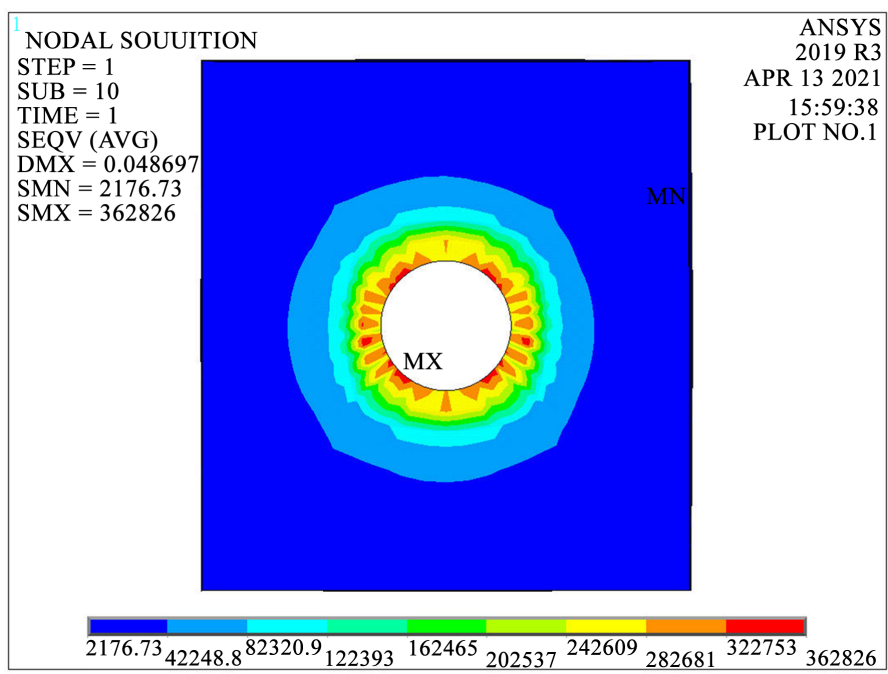

Figure 17. The first load stress distribution of the end plate.

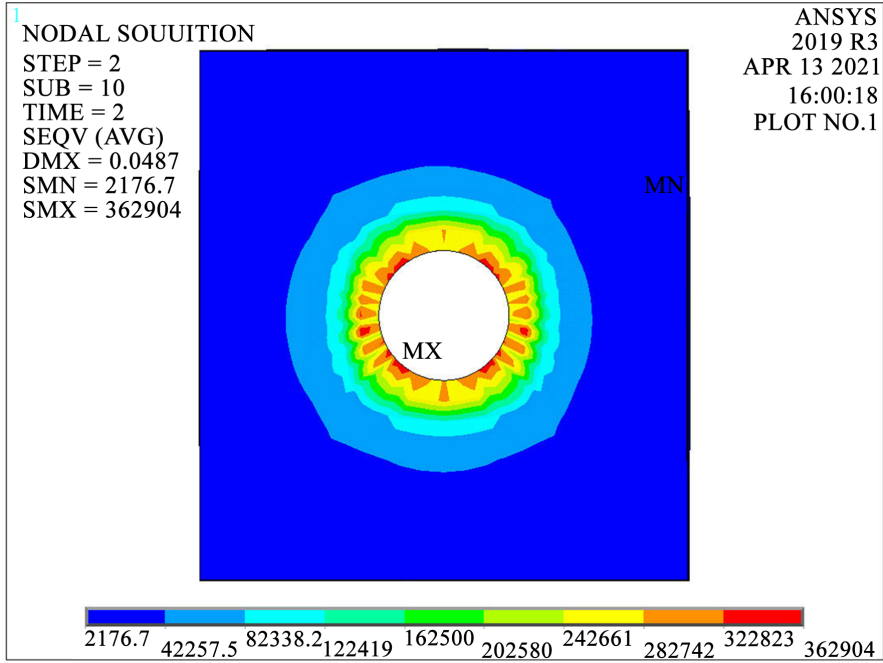

Figure 18. The second step load stress distribution of the end plate. 


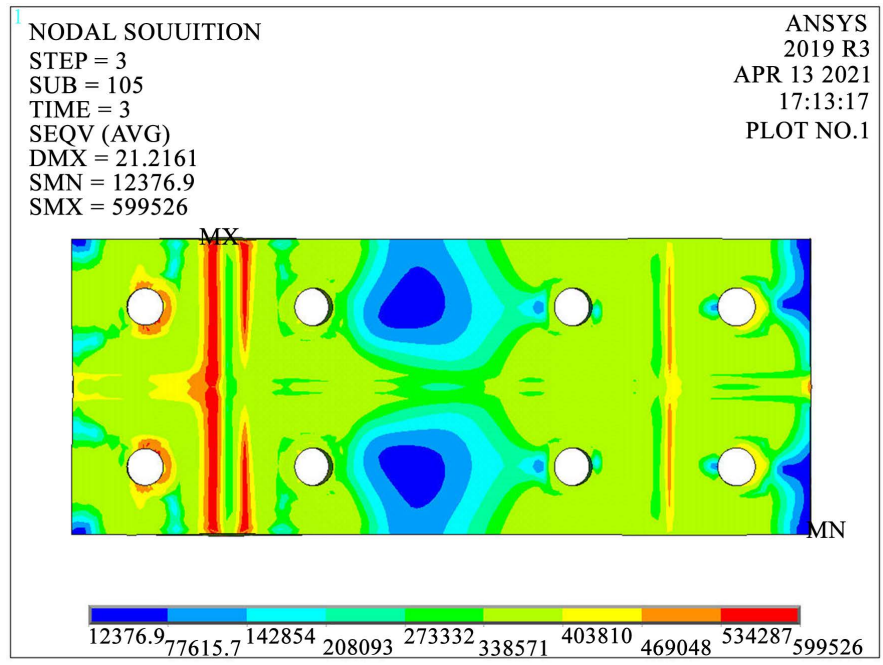

Figure 19. Von mise cloud diagram of end plate.

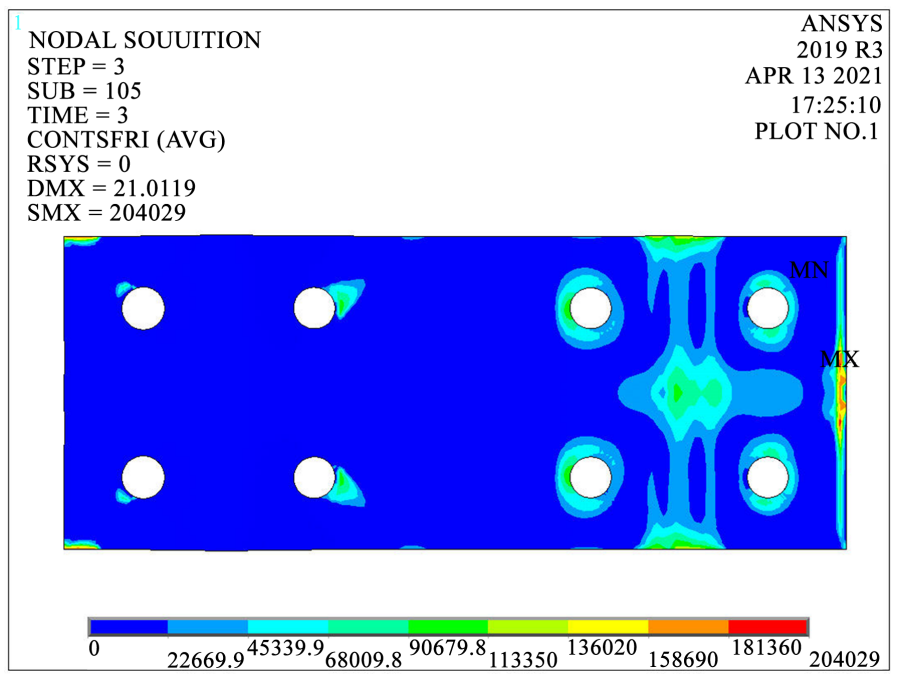

Figure 20. Friction stress distribution of end plate.

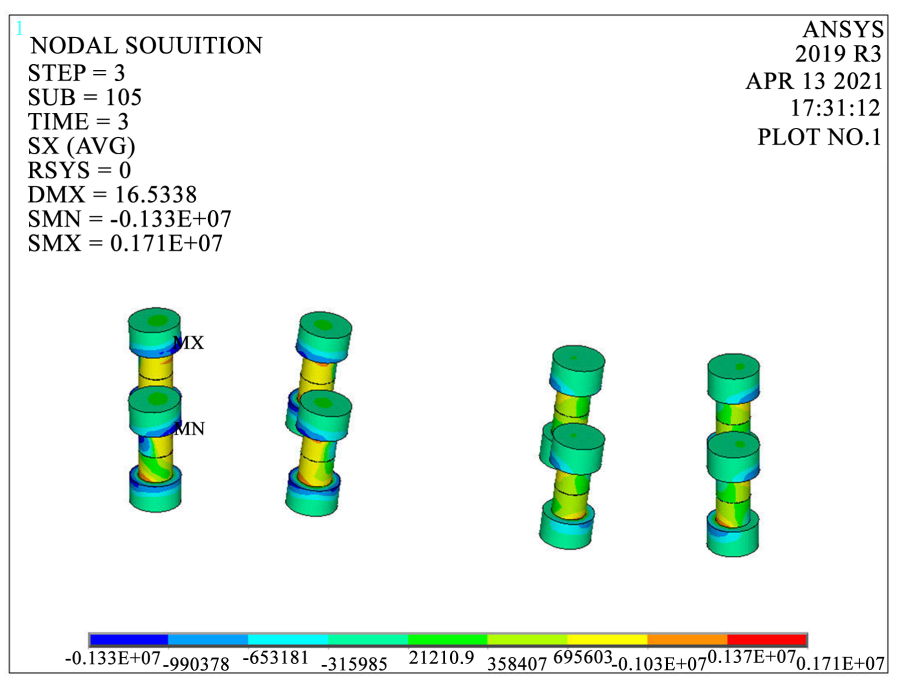

Figure 21. Bolt Von mise cloud diagram. 


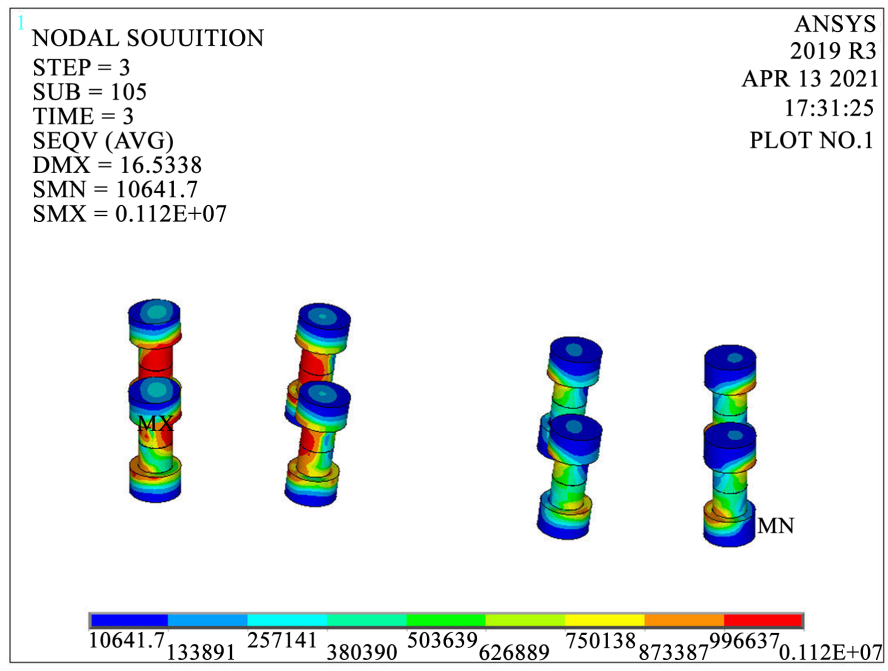

Figure 22. Bolt X-component of stress cloud diagram.

contact part between the two rows of bolts on the left and the end plate during the load application process is subjected to compressive stress under the action of the bending deformation of the end plate. And the von mise stress on the inner side of the rod adjacent to this part is the largest.

\section{Conclusions}

This paper uses ANSYS finite element analysis software to simulate and analyze the beam-column joint test, and get the following conclusions:

1) The contact parts of the first and second rows of tension bolts and the end plate at the node domain are subjected to compressive stress under the action of bending and deformation of the end plate, and the inner side of the screw adjacent to this part bears the greatest stress.

2) Through the comparative analysis of the ideal elastoplastic material model, the three-line material model and the four-line material constitutive model, it can be obtained that the four-line material model can better simulate the rotation performance of the node, which is accurate for future finite element analysis. Sex provides a strong guarantee.

3) In the next step, the finite element model established in this paper can be used to perform a large number of finite element parameter analysis on end plate connection nodes of different structures to obtain an accurate and comprehensive understanding of its force characteristics, so as to establish a complete analysis model and design method.

\section{Conflicts of Interest}

The author declares no conflicts of interest regarding the publication of this paper.

\section{References}

[1] Krishnamurthy, N., Avery, L.K., Jeffrey, P.K., et al. (1979) Analytical M- $\theta$ Curves 
for End-Plate Connections. Journal of the Structural Division, 105, 133-145. https://doi.org/10.1061/JSDEAG.0005073

[2] Krishnamurthy, N. (1980) Modelling and Prediction of Steel Bolted Connection Behavior. Computers \& Structures, 11, 75-82.

https://doi.org/10.1016/0045-7949(80)90148-0

[3] Maxwell, S.M., Jenkins, W.M. and Howlett, J.H. (1981) A Theoretical Approach to the Analysis of Connection Behavior. Joints in Structural Steelwork.

[4] Shi, G. (2004) Research on Static and Seismic Performance of Semi-Rigid End Plate Connections in Steel Frames. Tsinghua University, Beijing.

[5] Liu, W. (2016) Design Theory and Method of Semi-Rigid Connection Steel Frame. Southeast University, Nanjing.

[6] Guo, C., Liu, X.L. and Zhang, R. (2013) Research on Finite Element Simulation Method of High-Strength Bolt Extension End Plate Connection. Journal of Qingdao Technological University, 34, 20-28.

[7] Wang, Y., Sun, Y., Liu, X.L. (2011) Analysis of Mechanical Performance of High-Strength Bolt Extension End Plate Connection. Steel Structure, 26, 1-10.

[8] Wang, D.Y. (2014) Research on Static Performance of End-Plate Connection Joints in Steel Structure with Super Large Bearing Capacity. Beijing Jiaotong University, Beijing.

[9] Sun, Y. (2010) Research on the Force Characteristics of the High-Strength Bolts Connected with the Overhanging end Plate. Qingdao Technological University, Qingdao.

[10] European Committee for Standardization. (2003) Eurocode 3: Design of Steel Structures, Part1.8: Design of Joints, prEN1993-1-8.

[11] Guan, J., Wang, Y.Q., Zhang, Y. and Shi, Y.J. (2012) Factors Influencing the Compressive Performance of High-Strength Bolted Joints of Stainless Steel Components. Journal of Beijing Jiaotong University, 36, 115-120.

[12] Shi, G., Shi, Y.J. and Wang, Y.Q. (2008) Nonlinear Finite Element Analysis of Beam-Column End-Plate Connection in Steel Frame. Engineering Mechanics, 25, 79-85.

[13] Jin, M. and Zhang, Z.M. (2012) Finite Element Analysis of Steel Frame Beam-Column End Plate Connection. Journal of Beijing Jiaotong University, 36, 121-126.

[14] Wen, D.W. (2007) Analysis of the Performance of Semi-Rigid Joints in Steel Frame with Extended End Plates. Southwest Jiaotong University, Chengdu. 